\title{
Pattern of Malocclusion in Orthodontic Patients in South-Eastern Region of Nepal
}

\author{
Dr Anand Acharya, ${ }^{1}$ Dr Bhushan Bhattarai, ${ }^{2}$ Dr Diana George, ${ }^{3}$ Dr Tarakant Bhagat ${ }^{4}$ \\ 2.3Lecturer, Dept of Orthodontics, Nobel Medical College, Biratnagar \\ ${ }^{4}$ Asso Professor, Dept of Public Health Dentistry, BP Koirala Institute of Health Sciences, Dharan, Nepal
}

Correspondence: Dr Anand Acharya; Email: dranandacharya@gmail.com

\section{ABSTRACT}

Introduction: Occlusal traits in orthodontic patients have been studied in different parts of Nepal. However, very few data are available on malocclusion in south-eastern region of Nepal.

Objective: To assess the pattern of malocclusion occurring in orthodontic patients in south-eastern region of Nepal, and to estimate the age of presentation of Class II malocclusion among the patients.

Materials \& Method: Data were collected from 150 pre-treatment study models and lateral cephalograms from two orthodontic specialty clinics in Biratnagar. Angle's classification system was used to determine dental malocclusion and ANB angle was used to determine skeletal malocclusion. Chi square test was used to test the association between dental and skeleton malocclusions.

Result: Angle's Class I malocclusion was found in 95(63.33\%), Class II Div 1 in 41 (27.33\%), Class II Div 2 in 13(8.66\%) and Class III in $1(0.66 \%)$. Among all subjects; 119 (79.33\%) had skeletal Class I, 24(16\%) had skeletal Class II and 7(4.66\%) had skeletal Class III. There was significant association between dental and skeletal malocclusions. The average age for reporting Class II Div 1 malocclusion was 16.5 years and Class II Div 2 malocclusion was 19 years.

Conclusion: Angle's Class I is the most common malocclusion followed by Class II and Class III among orthodontic patients in south-eastern Nepal. The subjects lack awareness on age factor for orthodontic treatment.

Keywords: Angle's classification, malocclusion, south-eastern Nepal

\section{INTRODUCTION}

Orthodontic and dentofacial orthopedic problems have been a major health concern in the community. Increasing public awareness and availability of orthodontic specialty services have led to increasing number of orthodontic patients in specialty clinics. Edward Angle classified malocclusion on the basis of antero-posterior relationship of the teeth in 1899.' In spite of several limitations; Angle's classification of malocclusion is still widely used.

Although many studies have been conducted regarding the type and distribution of malocclusion in different regions of $\mathrm{Nepal}^{2-{ }^{-7}}$ very few researches of such kind have been conducted in south-eastern Nepal. The objective of the study was to assess the pattern of distribution of malocclusion among orthodontic patients in south-eastern region of $\mathrm{Nepal}$, to determine the association between dental and skeletal malocclusion, and to estimate the age of presentation of Class II malocclusion among the patients.

\section{MATERIALS AND METHOD}

Data were collected from pretreatment models and lateral cephalometric radiographs of 150 (104 female and 46 male) patients reporting to two orthodontic specialty clinics in Biratnagar during July 2014 to June 2015. The samples were categorized on the basis of age group as: children (9-12 years), adolescents (1317 years) and adults (18-38 years). Ethical clearance was obtained from Institutional Review Committee of Nobel Medical College to conduct the study. Purposive sampling technique was used for this cross sectional study. Inclusion criteria were patients having case history record, pretreatment orthodontic casts and lateral cephalometric radiograph, presence of first permanent molars, patients with no history of trauma and previous history of orthodontic treatment. Angle's 
classification of malocclusion was used to classify the dental malocclusion using the study models. ANB angle were calculated manually according to Steiner skeletal parameters using lateral cephalograms. The data were analyzed for descriptive statistics and chi square test was used to test the association between dental and skeleton malocclusion. SPSS version 21 was used for statistical analysis.

\section{RESULT}

In the present study, the age of the subjects ranged from 9 to 38 years with the mean age 18.6 years. The samples comprised of 104 (69.33\%) females and 46 $(30.66 \%)$ males. The numbers of patients in children age group were 19 (12.66\%), adolescent group were 59 (39.33\%) and adult group were 72 (48\%).

The chief complaint for orthodontic treatment among the subjects according to case history record were: irregular front teeth $47.33 \%$, protrusion $29.33 \%$, spacing $14.66 \%$, irregular teeth with protrusion $4 \%$, difficulty in chewing $2 \%$, spacing with protrusion $2 \%$, and irregular teeth with spacing $0.66 \%$.

The distribution of malocclusion according to Angle's classification system is given in Table 1.

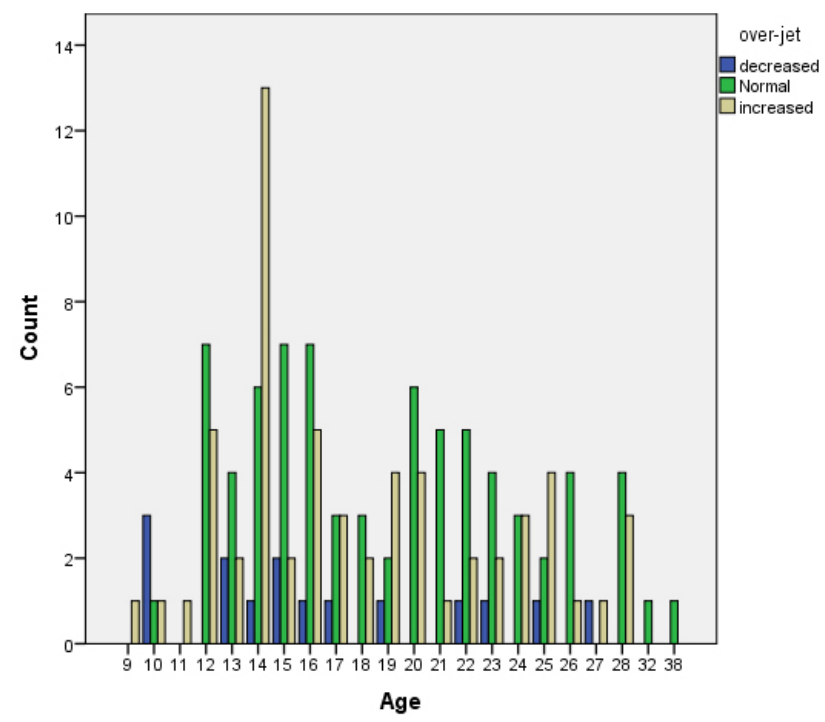

Figure 1: Age versus overjet bar chart
Table 1: Distribution of malocclusion

\begin{tabular}{|l|c|c|}
\hline Type of Malocclusion & Frequency & Percentage \\
\hline Class I & 95 & $63.33 \%$ \\
\hline Class II Div 1 & 41 & $27.33 \%$ \\
\hline Class II Div 2 & 13 & $8.66 \%$ \\
\hline Class III & 1 & $0.66 \%$ \\
\hline Total & 150 & $100 \%$ \\
\hline
\end{tabular}

The total number of samples with increased overjet was 60(40\%) and increased overbite was 70(46.66\%). Maximum number of patients with increased overjet and overbite were present at the age of 14 years. Among the overjet and overbite subjects; 13(65\%) presented with increased overjet and 15(75\%) presented with increased overbite at the age of 14 years (Figure 1,2).

The patients with Class II Division 1 malocclusion were presented for orthodontic treatment at the age of 16.5 years in males and 16.45 years in females. Similarly, the patients with Class II Division 2 malocclusion were presented at the age of 19 years in males and 18.33 years in females.

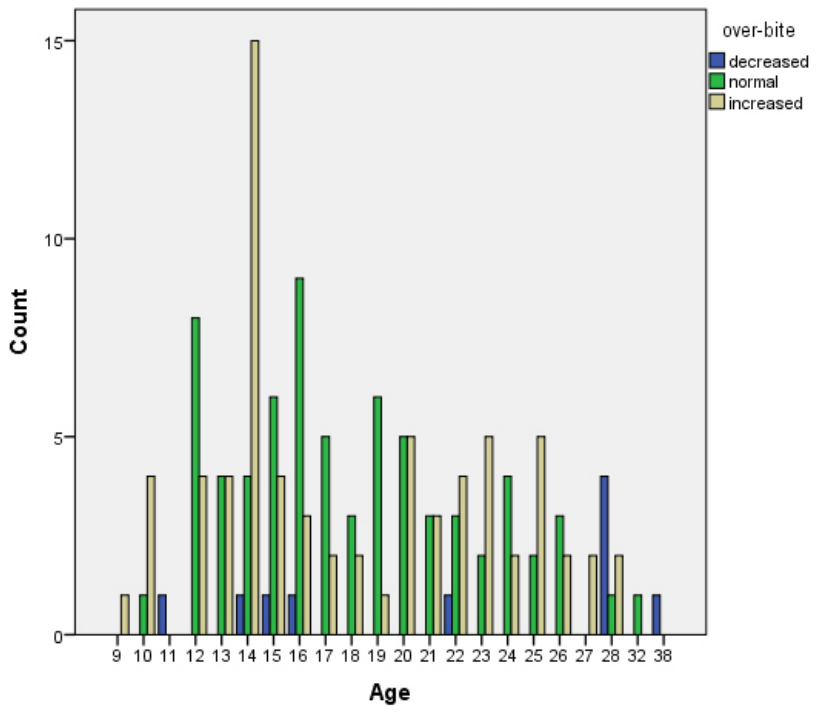

Figure 2: Age versus overbite bar chart

According to the cephalometric value of ANB angle; majority of the samples possessed skeletal Class I malocclusion pattern. Among all samples, 119 (79.33\%) had skeletal Class I, 24 (16\%) had skeletal Class II and remaining 7(4.66\%) had skeletal Class III base (Figure 3). 


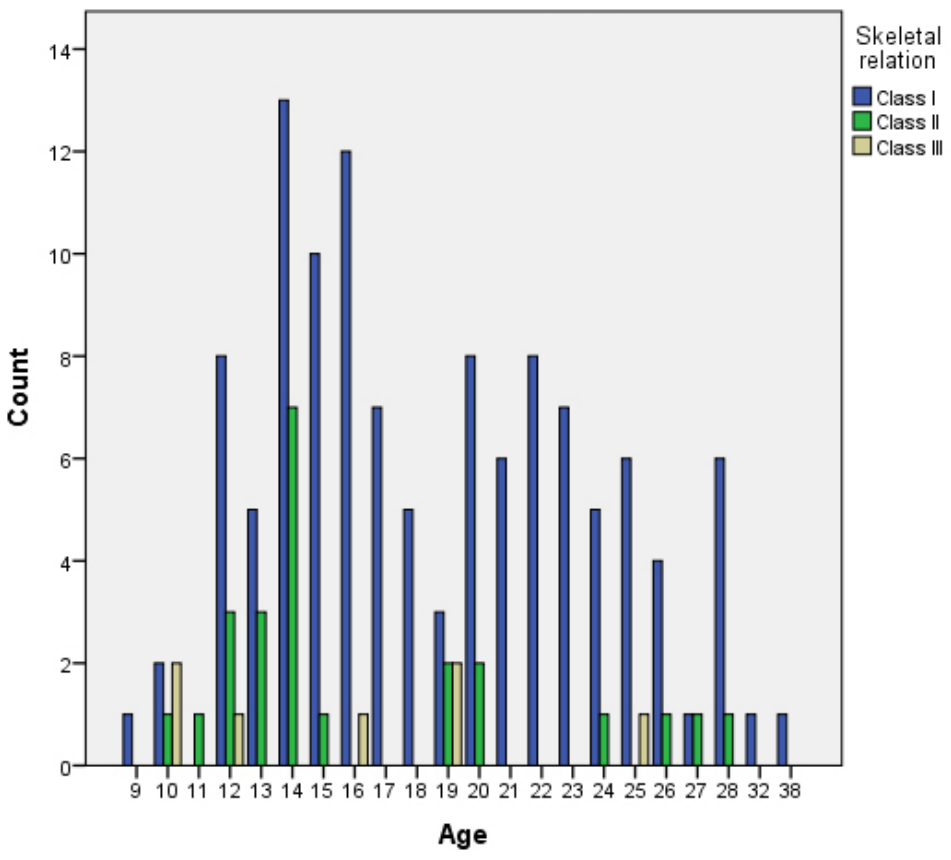

Figure 3: Age versus skeletal relation bar chart

The present study revealed the association between Angle's classification of malocclusion and underlying skeletal base as given by ANB angle (Table 2). There was a significant association between the two as tested by Pearson Chi square test $(p=0.001)$. On contrary, there was no significant association between gender and underlying skeletal base.

\section{DISCUSSION}

According to the present study, the number of female patients (69.33\%) is greater as compared to male patients $(30.66 \%)$. This finding clearly indicates that the females in south-eastern Nepali society are more concerned for orthodontic treatment. This fact is in consensus with the findings of other similar studies. Majority of our patients had chief complaint of irregular front teeth and protrusion which is also consistent with other similar researches. ${ }^{8-11}$

Angle's Class I malocclusion was found in $63.33 \%$ which is comparable to other reports. ${ }^{2,3,7,12}$ Class II malocclusion was found in $36 \%$ of the patients which is slightly higher than the similar report in the sample of Sunsari district. ${ }^{2}$ Among Class II malocclusion; Class II Div 1 malocclusion was found in $75.92 \%$ where as Class II Div 2 was seen in $24.08 \%$ as compared to $88.3 \%$ and $11.6 \%$ respectively according to the study conducted by Sharma. ${ }^{2}$
Table 2: Association between dental and skeletal malocclusion

\begin{tabular}{|l|c|c|c|}
\hline Type of Malocclusion & Dental & Skeletal & p-Value \\
\hline Class I & $95(63.33 \%)$ & $119(79.33 \%)$ & \multirow{2}{*}{$0.001^{*}$} \\
\cline { 1 - 3 } Class II & $54(36.0 \%)$ & $24(16.0 \%)$ & \\
\cline { 1 - 3 } Class III & $1(0.66 \%)$ & $7(4.66 \%)$ & \\
\cline { 1 - 3 }
\end{tabular}

*Significant at $p \leq 0.001$

Similarly, Angle's Class III malocclusion was seen in only $0.66 \%$ of the sample studied although the skeletal Class III malocclusion was seen in $4.66 \%$ of the patients. This was not in consistent with the findings of similar study done in Dharan. ${ }^{2}$ This variation may be due to decreased incidence of Angle's Class III malocclusion in south-eastern region.

In the present study, the highest number of patients (48\%) belonged to adult age group followed by adolescent and children group. This sequence was consistent with the findings of Halwai et al conducted in mid-western Nepal. ${ }^{6}$ Piya et al found highest number of orthodontic patients in adolescent age group. ${ }^{4}$ The difference could be due to higher consciousness for esthetics and sound economic condition of the patients in adult age group among the present sample.

In the present study, $40 \%$ samples presented with increased overjet and $46.66 \%$ presented with increased overbite. These figures are higher than the 
school children of eastern Nepal as reported by Singh et al. They found increased overjet in $17.51 \%$ and deep overbite in $13.23 \%$. $^{3}$ However, Shrestha and Shrestha reported increased overjet in $43.8 \%$ subjects and increased overbite in $20.7 \% .^{5}$

The significant association found between Angle's classification of malocclusion and underlying skeletal base is in accordance with the findings of Patrick et al. The authors reported no significant association between gender and underlying skeletal base; which is also in accordance with the present study..$^{13}$

\section{CONCLUSION}

Angle's Class I is the most common malocclusion followed by Class II and Class III malocclusions in south-eastern Nepali orthodontic patient sample. The average age of presentation of malocclusion among south-eastern Nepali patients is above 16 years for Class I| Division 1 and above 18 years for Class II Division 2 malocclusion; indicating the late awareness for orthodontic treatment. Priority should be given to raise public awareness regarding the age factor in orthodontic treatment.

\section{OJN}

\section{REFERENCES}

1. Angle E H. Classification of Malocclusion. Dental Cosmos. 1899; 41 (3):248-64.

2. Sharma JN. Pattern of distribution of malocclusions in patients seeking orthodontic treatment at BPKIHS from Sunsari District of Nepal. Health Renaissance. 2010; 8(2):93-6.

3. Singh VP, Sharma A. Epidemiology of malocclusion and assessment of orthodontic treatment need for Nepalese children. International Scholarly Research Notices. 2014.

4. Piya A, Shrestha VB, Acharya J, Khanal S, Bhattarai P. Pattern of distribution of malocclusion among patients seeking orthodontic treatment at dental college- Nepal Medical College. J Nep Dent Asso. 2013; 13(2):36-41.

5. Shrestha S, Shrestha RM. An analysis of malocclusion and occlusal characteristics in Nepalese orthodontic patients. Orthod J Nep. 2013; 3(1):19-25.

6. Halwai HK, Gautam V, Pandey M. Distribution of different skeletal pattern in patients seeking orthodontic treatment in mid-western Nepal. Orthod J Nep. 2016; 6(2):7-9.

7. Baral P. Prevalence of Malocclusion in Western Nepal. Orthod J Nep. 2015; 5(2):6-8.

8. Yang WS. The study on the orthodontic patients who visited department of Orthodontics, Seoul, National University Hospital. Taehan Chikkwa Uisa Hyophoe Chi. 1990; 28:811-21.

9. Obauni KO, Ogunbanjo BO. The pattern of malocclusion at the orthodontic unit, Lagos State University Teaching Hospital. Nigerian J Clin Med. 2009; 2:1

10. Tausche E, Luck O, HarzerW. Prevalence of malocclusions in the early mixed dentition and orthodontic treatment need. Eur J Orthod. $2004 ; 26: 237-44$.

11. Saqib N, Saqib SAS, Wahid M. Orthodontic treatment need at de Montomorency College of Dentistry Lahore using aesthetic component of IOTN index. Pak Oral Dent J. 2007; 28(1):83-86.

12. Rasheed TA, Muhammad NA, Occlusal Features among teenager patients attending peramerd specialized dental center in Sulaimani City, J A Social Sci Humanities. 2016; 2:2:20-4.

13. Patrick M, Mao J, Tecian M, Sapkota D K. Sagittal skeletal jaw base and dental arch relationships among adult orthodontic patients: A CBCT synthesized cephalogram analysis. J Dent Med Sci. 2016; 15(6):43-50. 